\title{
A field study to estimate the impact of noise barriers on mitigation of near road air pollution
}

\author{
Ranga Rajan Thiruvenkatachari ${ }^{1} \cdot$ Yifan Ding $^{1} \cdot$ David Pankratz $^{1} \cdot$ Akula Venkatram $^{1}$
}

Received: 24 August 2021 / Accepted: 4 October 2021 / Published online: 10 November 2021

(C) The Author(s) 2021

\begin{abstract}
Air pollution associated with vehicle emissions from roadways has been linked to a variety of adverse health effects. Wind tunnel and tracer studies show that noise barriers mitigate the impact of this pollution up to distances of 30 times the barrier height. Data from these studies have been used to formulate dispersion models that account for this mitigating effect. Before these models can be incorporated into Federal and State regulations, it is necessary to demonstrate their applicability under real-world conditions. This paper describes a comprehensive field study conducted in Riverside, CA, in 2019 to collect the data required to evaluate the performance of these models. Eight vehicles fitted with $\mathrm{SF}_{6}$ tracer release systems were driven in a loop on a $2-\mathrm{km}$ stretch of Interstate 215 that had a 5-m tall noise barrier on the downwind side. The tracer, $\mathrm{SF}_{6}$, was sampled at over 40 locations at distances ranging from 5 to $200 \mathrm{~m}$ from the barrier. Meteorological data were measured with several 3-D sonic anemometers located upwind and downwind of the highway. The data set, corresponding to $10 \mathrm{~h}$ collected over 4 days, consists of information on emissions, tracer concentrations, and micrometeorological variables that can be used to evaluate barrier effects in dispersion models. An analysis of the data using a dispersion model indicates that current models are likely to overestimate concentrations, or underestimate the mitigation from barriers, at low wind speeds. We suggest an approach to correct this problem.
\end{abstract}

Keywords Field study $\cdot$ Noise barrier $\cdot$ Air pollution $\cdot$ Mitigation $\cdot$ Low winds $\cdot$ Near-road air quality $\cdot$ Tracer gas study

\section{Introduction}

Near-road air pollution from vehicle emissions is correlated with adverse health impacts (Chen et al. 2019; Brandt et al. 2014). Results from a tracer study in which the noise barrier was simulated with a 6-m hay bale barrier indicate that near-road noise barriers have a mitigating impact on near road concentrations (Finn et al. 2010): the concentrations relative to those in the absence of the barrier were reduced by as much as $80 \%$ next to the barrier and about an average of $70 \%$ over a downwind distance of 30 times the barrier height. A wind tunnel study examining the effects of different road configurations measured concentration reductions ranging from $40 \%$ next to the barrier to $20 \%$ at downwind distances of 40 times the barrier height (Heist et al. 2009). A field experiment on adjacent sections of highways with and

Akula Venkatram

akula.venkatram@ucr.edu

1 Department of Mechanical Engineering, University of California, Riverside, CA 92521, USA without noise barriers showed lower concentrations downwind of the noise barrier (Baldauf et al. 2008).

A wind tunnel study (Heist et al. 2009) showed that noise barriers reduce ground-level concentrations downwind of the barrier by lifting the plume from a line source over the barrier. This plume is then entrained into the recirculating wake of the barrier resulting in a concentration profile that is relatively uniform through the height of the barrier. This well-mixed region persists for downwind distances of about ten times the barrier height. The qualitative features of these observations have been reproduced by Hagler et al. (2011) using a computational fluid dynamics (CFD) model.

The data from the tracer field study (Finn et al. 2010) and the wind tunnel (Heist et al. 2009) form the basis of a semiempirical model that accounts for the effects of a barrier on dispersion of emissions from a highway (Schulte et al. 2014). The major features of this model have been incorporated into a non-regulatory version of AERMOD (Cimorelli et al. 2005), the USEPA's regulatory model for short-range dispersion. The performance of this version of the model has not yet been evaluated under real-world conditions in which 
the geometry of the urban highway and the meteorological conditions are far from the idealized conditions of the tracer field study and the wind tunnel. This paper describes a tracer field study designed to collect the data required to evaluate the performance of AERMOD under these conditions. We have also conducted a preliminary evaluation of the resulting data set using a dispersion model that accounts for the effects of a barrier.

\section{Field study}

\section{Site}

The study was conducted on a portion of Interstate- 215 freeway passing through the University of California, Riverside (UCR) campus. The freeway runs from north-northwest to south-southeast as shown in Fig. 1. A single noise barrier almost parallel to the freeway is located towards the east of the freeway. The noise barrier is about 5-m high and is approximately $1.3-\mathrm{km}$ long. The highway and the barrier curve to the east near the southern edge of the barrier. The three outermost lanes on each side of the freeway were used in the study. The aerial view of the study region is shown in Fig. 1. The study was conducted on four different days to capture different atmospheric stability conditions. Table 1 provides the dates of the study days and the time intervals when the measurements were made.

\section{Tracer release system}

Custom-built tracer gas release systems were fitted to eight road vehicles, which were driven on Interstate-215 in a loop that enclosed the path shown in Fig. 1. The release system consisted of a cylinder containing pure $S F_{6}$ with a pressure regulator as shown in Fig. 2. The pressure regulator was attached to an electronic solenoid that could be controlled from inside the vehicle. The solenoid opened the gas flow to a mass flow controller that was controlled by an Arduino computer. A GPS unit on the roof of the vehicle fed the
Fig. 1 Aerial view of the study region. The receptor locations are marked with yellow circles, the red lines are the paths along which the vehicles released $\mathrm{SF}_{6}$, the noise barrier runs along the blue line, and the red triangles show the locations where the meteorological data was collected

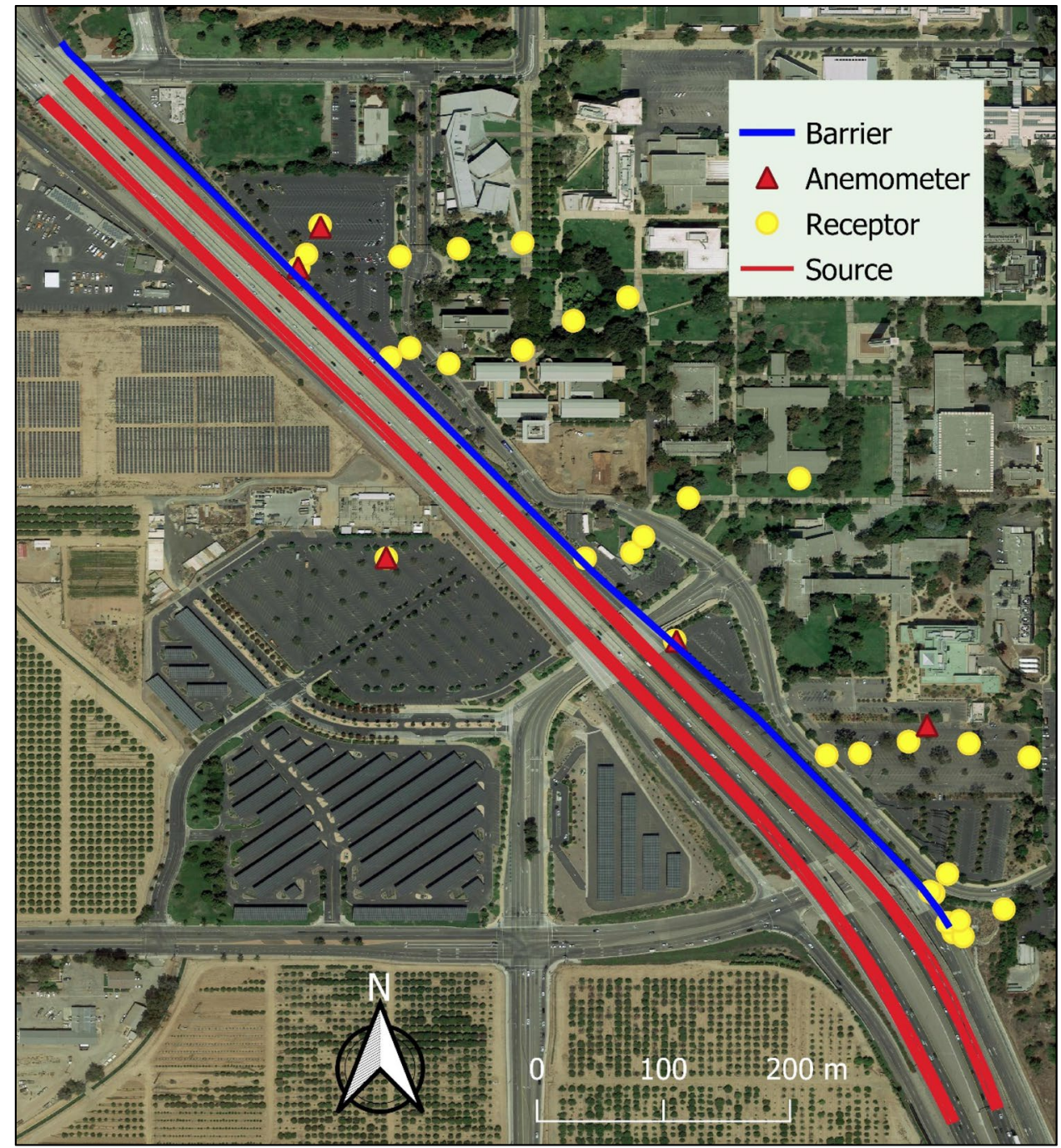


Table 1 Dates of study days and the measurement time intervals

\begin{tabular}{lllll}
\hline Date & $7 / 30 / 2019$ & $8 / 6 / 2019$ & $8 / 13 / 2019$ & $8 / 20 / 2019$ \\
\hline Study day & $\mathbf{1}$ & $\mathbf{2}$ & $\mathbf{3}$ & $\mathbf{4}$ \\
Exp 1 (background) & $13: 00-13: 30$ & $15: 00-15: 30$ & $20: 00-20: 30$ & $18: 00-18: 30$ \\
Exp 2 & $14: 00-14: 30$ & $16: 00-16: 30$ & $21: 00-21: 30$ & $19: 00-19: 30$ \\
Exp 3 & $14: 30-15: 00$ & $16: 30-17: 00$ & $21: 30-22: 00$ & $19: 30-20: 00$ \\
Exp 4 & $15: 00-15: 30$ & $17: 00-17: 30$ & $22: 00-22: 30$ & $20: 00-20: 30$ \\
Exp 5 & $15: 30-16: 00$ & $17: 30-18: 00$ & $22: 30-23: 00$ & $20: 30-21: 00$ \\
Exp 6 & $16: 00-16: 30$ & $18: 00-18: 30$ & $23: 00-23: 30$ & $21: 00-21: 30$ \\
\hline
\end{tabular}

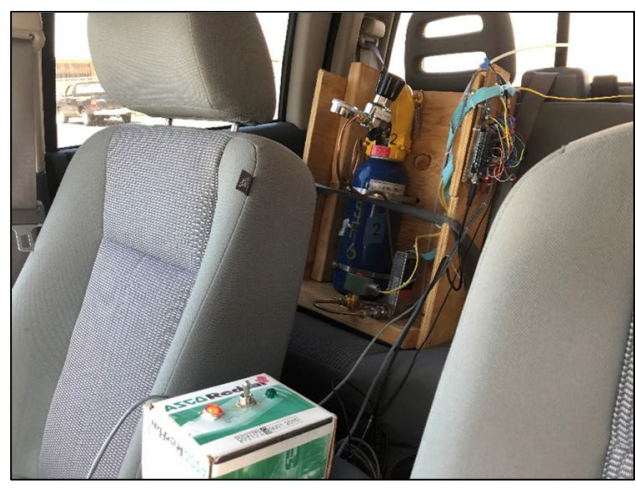

(a)

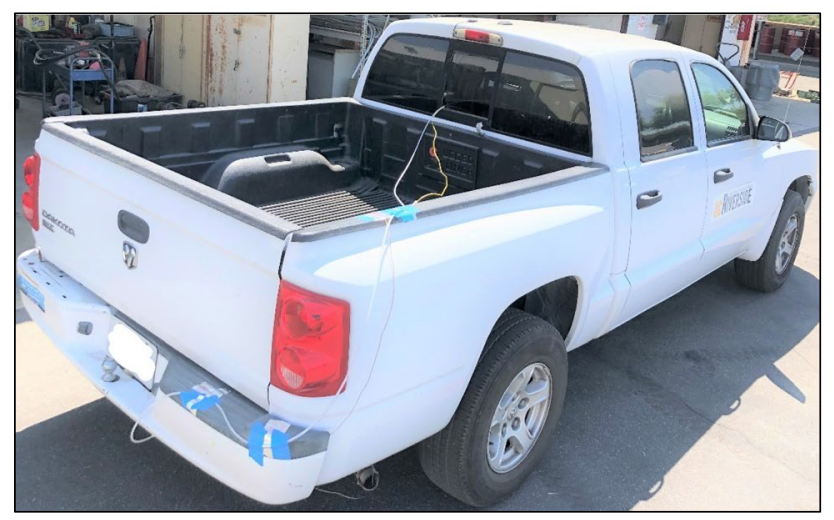

(b)

Fig. 2 a Picture of the $S F_{6}$ gas cylinder with the pressure regulator, the electronic solenoid (green and white box) that could be operated from within the vehicle, and the mass flow controller. b The $S F_{6}$ gas from the mass flow controller was looped into the vehicle exhaust

location data to the computer. The mass flow controller was programmed to provide a full release rate of $42 \mathrm{ml} / \mathrm{s}$ when vehicle speeds were above $100 \mathrm{~km} / \mathrm{h}$. The release rate linearly reduced with decreasing vehicle speed to simulate exhaust emissions from vehicles. The outlet flow from the mass flow controller was looped into the vehicle exhaust.

The vehicles started about 1-min apart from each other to obtain a uniform release. The gas cylinders were weighed before and after each study period to determine the total gas
Table 2 Total tracer gas released on each study day

\begin{tabular}{ll}
\hline Day & $\begin{array}{l}\text { Tracer } \\
\text { released } \\
(\mathrm{kg})\end{array}$ \\
\hline 1 & 1.990 \\
2 & 2.620 \\
3 & 1.900 \\
4 & 2.225 \\
\hline
\end{tabular}

released. The tracer gas released on each study day is shown in Table 2.

\section{Samplers}

A total of 46 air samplers were used in the study. The sampler locations on one of the study days are shown in Fig. 1. As winds were expected to be predominantly westerly, downwind samplers were placed east of the sound barrier while a single upwind sampler was placed west of the freeway. All the samplers had inlets at a height of $1.8 \mathrm{~m}$ except a few that had inlet heights of $0.5 \mathrm{~m}, 1 \mathrm{~m}, 3 \mathrm{~m}$, and $5 \mathrm{~m}$ from the ground.

Each sampler consisted of 6 pumps and each pump was connected to a 12-1 polyethylene bag. An air sampler system used in the study is shown in Fig. 3a. A single-board computer (Z-World Rabbit Model 1810) with drivers to control each sample pump formed the timer system. The samplers were programmed to collect integrated 30-min air samples. The first experiment on each study day was conducted $45 \mathrm{~min}$ before the start of the tracer release to measure background concentrations while subsequent experiments were conducted every $30 \mathrm{~min}$ with the second experiment beginning $15 \mathrm{~min}$ after the start of the tracer release.

The collected samples were taken to a laboratory at UCR CE-CERT for analysis using the system shown in Fig. 3b. All six bags from three samplers could be sampled simultaneously using the custom-built auto-sampler system. Pumps and solenoid valves were used to control the flow of the samples. The samples were measured using a bank of Agilent Technology $6890 \mathrm{~N}$ electron capture (ECD) gas 
Fig. 3 a Inside of the sampler system containing six pumps and six bag samplers. b Custom built analysis system used in the study to measure $S F_{6}$ concentrations in the collected samples

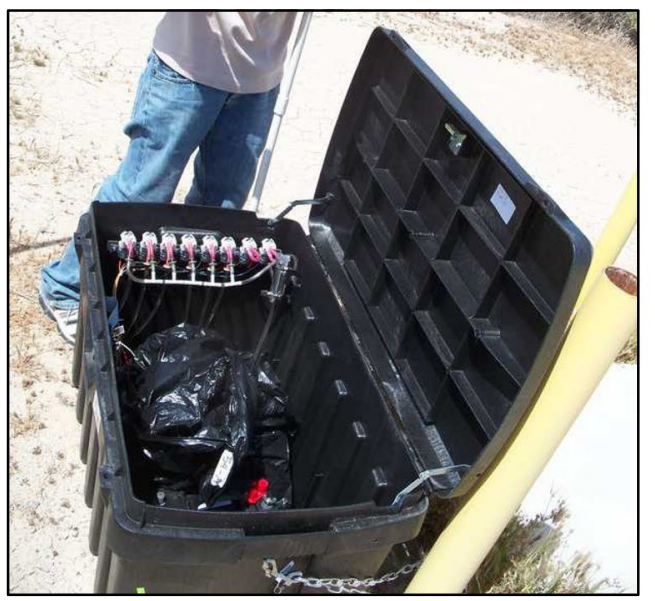

(a)

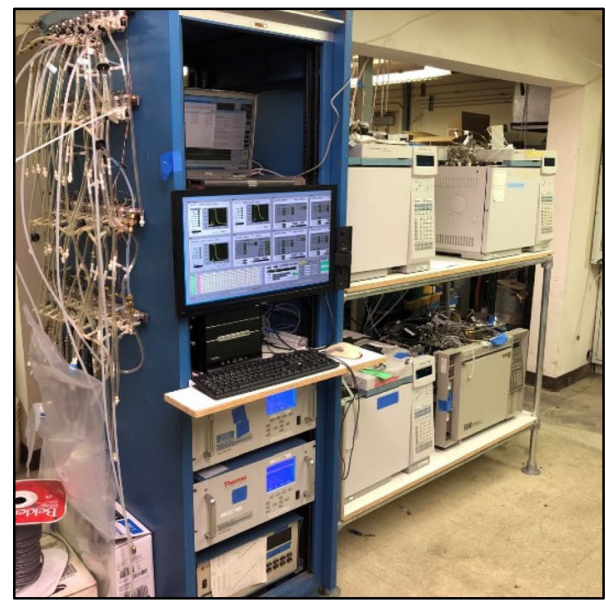

(b) chromatographs (GC) equipped with a 1/8-inch diameter Molecular Sieve 5A column and multi-port gas sampling valves.

\section{Meteorological and air quality data}

The meteorological data was collected using six 3-D Sonic Anemometers. The locations of the anemometers are shown in Fig. 1. Two of the sonics (RM Young Model 81,000) were placed towards the west (upwind) of the freeway mounted at $3 \mathrm{~m}$ and $5 \mathrm{~m}$ on a tower (Fig. 4), while the four remaining sonics (Campbell Scientific Model CSAT3) were placed east (downwind) of the freeway at a height of $2 \mathrm{~m}$. The meteorological data was recorded with a frequency of $20 \mathrm{~Hz}$. The meteorological data from the upwind sonic anemometer, mounted $5 \mathrm{~m}$ above ground level, were used in the dispersion model to interpret concentration measurements from the field study.

Table 3 summarizes the meteorological data collected by the upwind sonic at a height of $5 \mathrm{~m}$ where $Q$ is the kinematic heat flux, $u_{*}$ is the friction velocity, and $L$ is the Monin-Obukhov length. On days 3 and 4, the studies were conducted in the late evening hours when the sun had set, but the surface heat fluxes remained positive, though they were relatively small. This suggests that heat fluxes in this urban area are affected by advection of colder rural air onto a warmer urban surface.

On day 3 , the wind speeds and consequently the surface friction velocities were relatively small compared to the values on the other days. This has an impact on model performance as we will see later.

Figure 5 shows the variation of the measured $\mathrm{SF}_{6}$ concentration as a function of the distance from the barrier. The vertical axis represents the ratio of the measured concentration to the maximum concentration, measured during

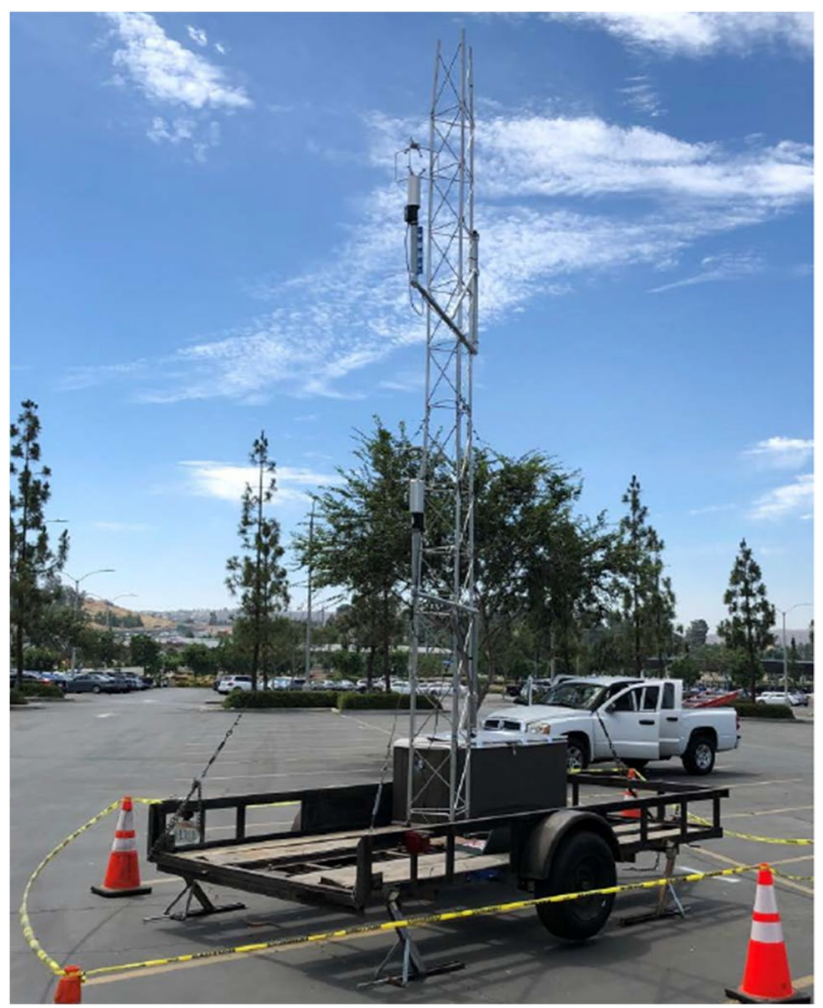

Fig. 4 Upwind meteorological measurement site containing two 3-D sonic anemometers mounted $3 \mathrm{~m}$ and $5 \mathrm{~m}$ above the ground

the 1-h averaging period, and the horizontal axis represents the perpendicular distance from the barrier.

The solid lines correspond to the ratios estimated from the dispersion model (Venkatram and Schulte 2018) that accounts for the effects of the barrier as follows,

$C\left(x_{b}\right)=\sqrt{\frac{2}{\pi}} \frac{q}{W \sigma_{w}} \ln \left(1+\frac{W}{x_{b}+\frac{h_{o} U_{e} \cos \theta}{\sigma_{w}}}\right)$ 
Table 3 Summary of meteorological data collected at the upwind side of the freeway at a height of $5 \mathrm{~m}$

\begin{tabular}{|c|c|c|c|c|c|c|}
\hline \multirow[t]{2}{*}{ Experiment } & \multicolumn{3}{|l|}{ Day 1} & \multicolumn{3}{|l|}{ Day 2} \\
\hline & $Q(K . m / s)$ & $u_{*}(m / s)$ & $L(m)$ & $Q(K . m / s)$ & $u_{*}(\mathrm{~m} / \mathrm{s})$ & $L(m)$ \\
\hline 1 (background) & 0.260 & 0.30 & -8.0 & 0.215 & 0.45 & -34.2 \\
\hline 2 & 0.261 & 0.45 & -27.7 & 0.215 & 0.53 & -56.0 \\
\hline 3 & 0.263 & 0.52 & -41.1 & 0.188 & 0.51 & -56.7 \\
\hline 4 & 0.257 & 0.49 & -36.2 & 0.170 & 0.47 & -48.5 \\
\hline 5 & 0.218 & 0.47 & -37.8 & 0.133 & 0.44 & -49.6 \\
\hline 6 & 0.227 & 0.46 & -34.0 & 0.110 & 0.47 & -73.1 \\
\hline \multirow[t]{2}{*}{ Exp } & Day 3 & & & Day 4 & & \\
\hline & $Q(K . m / s)$ & $u_{*}(\mathrm{~m} / \mathrm{s})$ & $L(m)$ & $Q(K . m / s)$ & $u_{*}(\mathrm{~m} / \mathrm{s})$ & $L(m)$ \\
\hline 1 (background) & 0.039 & 0.18 & -11.9 & 0.098 & 0.38 & -43.1 \\
\hline 2 & 0.019 & 0.14 & -10.3 & 0.052 & 0.38 & -84.1 \\
\hline 3 & 0.008 & 0.11 & -10.7 & 0.029 & 0.30 & -70.6 \\
\hline 4 & 0.016 & 0.13 & -9.5 & 0.028 & 0.19 & -17.9 \\
\hline 5 & 0.005 & 0.10 & -12.4 & 0.027 & 0.19 & -19.0 \\
\hline 6 & 0.011 & 0.06 & -1.5 & 0.011 & 0.14 & -21.0 \\
\hline
\end{tabular}

where $q$ is the emission rate per unit length, $h_{o}$ is the barrier height, $x_{b}$ is the perpendicular distance from the barrier, $W$ is the width of the road, $\sigma_{w}$ is the standard deviation of the vertical wind speed, $\theta$ is the angle between the wind direction and the perpendicular to the road, and $U_{e}$ is the effective wind speed. The maximum concentration used to normalize $C\left(x_{b}\right)$ is $C(0)$.

The model implies that the primary effect of the barrier is to shift the road sources upwind by a distance, $h_{o} U_{e} \cos \theta / \sigma_{w}$. We see that the downwind variation of the concentrations is consistent with this idea. The next section describes a model that includes more of the governing processes.

\section{Scaled barrier model}

The data collected in the field study were analyzed using a dispersion model that accounted for the two major effects of the barrier: lifting of the plume above the barrier followed by the entrainment of material in the plume into the wake downwind of the barrier. The plume from the source is first dispersed from its source neglecting the presence of the barrier. At the barrier, the vertical concentration profile resulting from dispersion upwind of the barrier is lifted to the top of the barrier by simply changing the vertical coordinate system used in describing the release so that the origin is at the top of the barrier: the new coordinate $z^{\prime}=z-h_{o}$, where $h_{o}$ is the barrier height. The entrainment into the wake is modeled by scaling the concentration profile above the barrier by a factor $f_{q}<1$ to account for the mass flux below the barrier. The vertical distribution beyond the barrier is given by

$$
\begin{array}{r}
F_{z}\left(x_{d}, z\right)=f_{q} D_{z}\left(x_{d}, z^{\prime}\right) ; \quad z>h_{o} \\
F_{z}\left(x_{d}, z\right)=f_{e} f_{q} D_{z}\left(x_{d}, 0\right) \quad z \leq h_{o} \\
D_{z}\left(x_{d}, z\right)=\frac{1}{\sqrt{2 \pi} U_{e} \sigma_{z}}\left\{\exp \left(\frac{-\left(z-z_{s}\right)^{2}}{2 \sigma_{z}^{2}}\right)+\exp \left(\frac{-\left(z+z_{s}\right)^{2}}{2 \sigma_{z}^{2}}\right)\right\}
\end{array}
$$

where $x_{d}$ is the effective distance downwind of the barrier, $\sigma_{z}$ is the vertical plume spread at this distance, $U_{e}$ is the effective horizontal velocity above barrier height, and $f_{e}$ is the entrainment factor. The calculation of these parameters is described later.

Note that the concentration below barrier height is constant. If the entrainment factor $f_{e}=1$, the concentration is continuous across $z=h_{o}$. A value $f_{e}<1$ results in a discontinuity in the concentration at the top of the barrier; this mimics the sharp increase in concentration at the top of the barrier measured in wind tunnel simulations (Heist et al. 2009). The scaling factor, $f_{q}$, can be derived from a mass balance based on unit emission rate from the source,

$f_{q}+f_{q} f_{e} D_{z}\left(x_{d}, 0\right) U_{b} h_{o}=1$

where the first term on the left-hand side is the horizontal mass flux above the barrier, and the second term is the flux below the barrier. The uniform velocity below barrier height, $U_{b}$, is the average velocity below the barrier height. The velocity profile is based on Monin-Obukhov similarity theory, where the values of the roughness length, $z_{o}$, the friction velocity, $u_{*}$, and the Monin-Obukhov length, $L$, are based on upwind micrometeorological measurements modified to account for barrier effects as discussed later.

Equation 3 yields

$f_{q}\left(x_{d}\right)=\frac{1}{1+f_{e} D_{z}\left(x_{d}, 0\right) U_{b} h_{o}}$.

The formulation for $f_{e}$ is discussed in the next section.

The concentration profile with and without the barrier is shown in Fig. 6. The concentration below the barrier height is constant and is lower than the concentration without the barrier. Above the barrier height, the concentration 

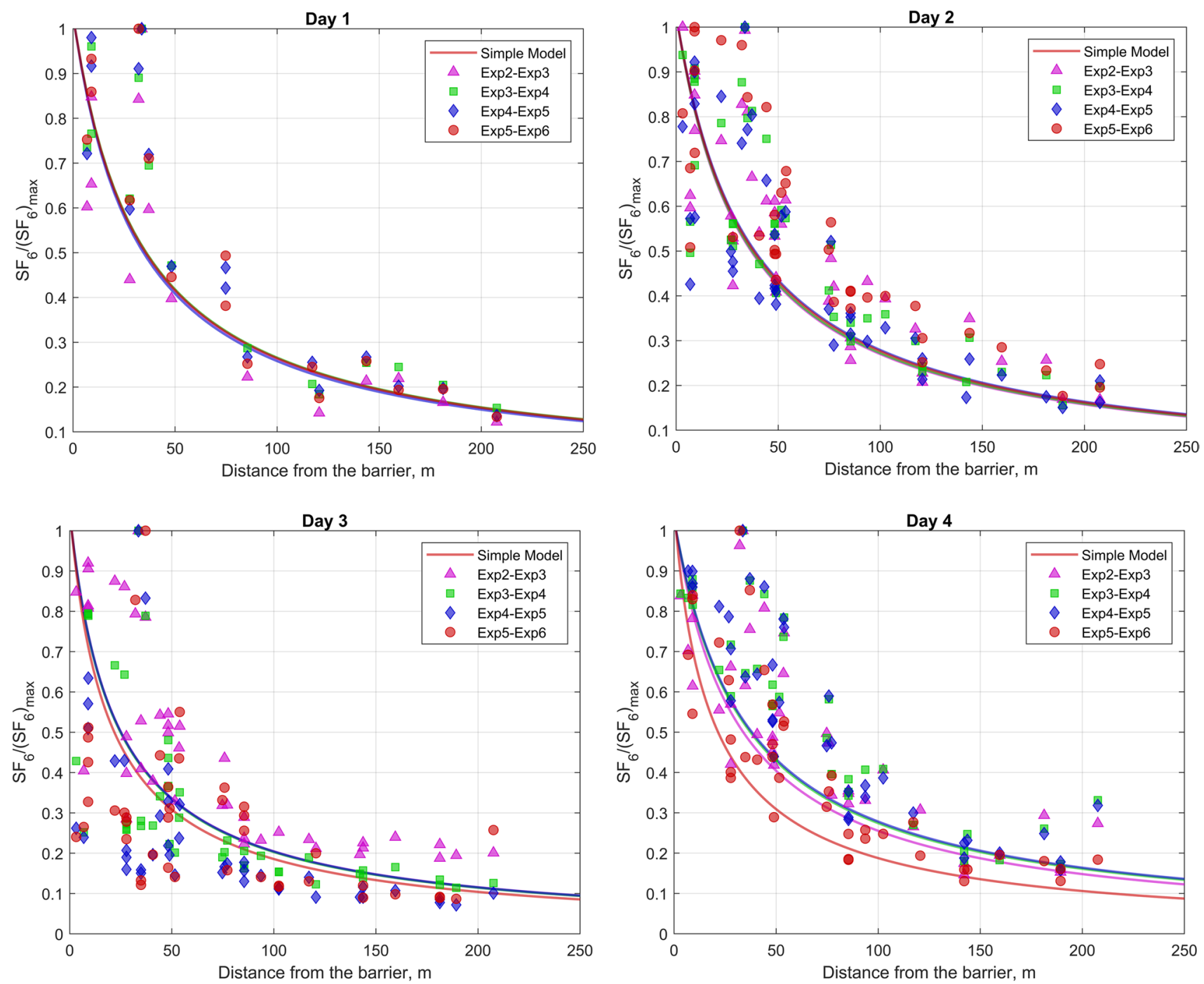

Fig. 5 Variation of the ratio of measured concentration to the maximum concentration, measured during the $1-\mathrm{h}$ averaging period, with the downwind distance from the barrier. The colored symbols repre-

sent the 1-h averaged measured concentration while the solid lines represent the ratio from Eq. 1. The colors of the solid lines correspond to the colors a used to depict the measured values

$t_{i}=\frac{y_{i}-y}{\sqrt{2} \sigma_{y}\left(x-x_{i}\right)}$

distribution follows a Gaussian profile: $f_{q} D_{z}\left(x_{d}, z^{\prime}\right)$. Note that the concentration profile assumes its near ground release shape when the barrier height, $h_{o}=0$. Also, the effect of the barrier becomes small as $D_{z}\left(x_{d}, 0\right)$ becomes small at large downwind distances.

In the model, the highway is represented as a set of sixline sources. The contribution from each line source to the concentration at a receptor when the wind is not perpendicular to the line source is obtained from the approximate expression (Venkatram and Horst 2006),

$C(x, y, z)=\frac{q}{\cos (\theta)}\left(\operatorname{erf}\left(t_{1}\right)-\operatorname{erf}\left(t_{2}\right)\right) F_{z}\left(x_{d}, z\right)$

where $q$ is the line source emission rate per unit length of the road, $x$ and $y$ are the receptor coordinates based on the coordinate system in which the $x$-axis is parallel to the wind direction, 1 and 2 correspond to the endpoints of the line source, $\theta$ corresponds to the wind direction with respect to the $x$-axis, $y_{i}-y$ is the distance of the endpoints from the receptor along the direction perpendicular to the wind direction, $\sigma_{y}\left(x-x_{i}\right)$ is the horizontal plume spread (Venkatram et al. 2013b) at the distance of the receptor from the two endpoints along the direction parallel to the wind, and $F_{z}\left(x_{d}, z\right)$ is the vertical distribution function discussed earlier. The effective downwind distance from the 
Fig. 6 Schematic showing the vertical concentration distribution of the scaled barrier model. The swirls indicate the recirculation zone formed behind the barrier and the inclined arrow indicates the lifting of the plume up to the barrier height. The well-mixed layer below the barrier and scaled concentration above it are shown by the blue line while the red line represents the distribution without any barrier

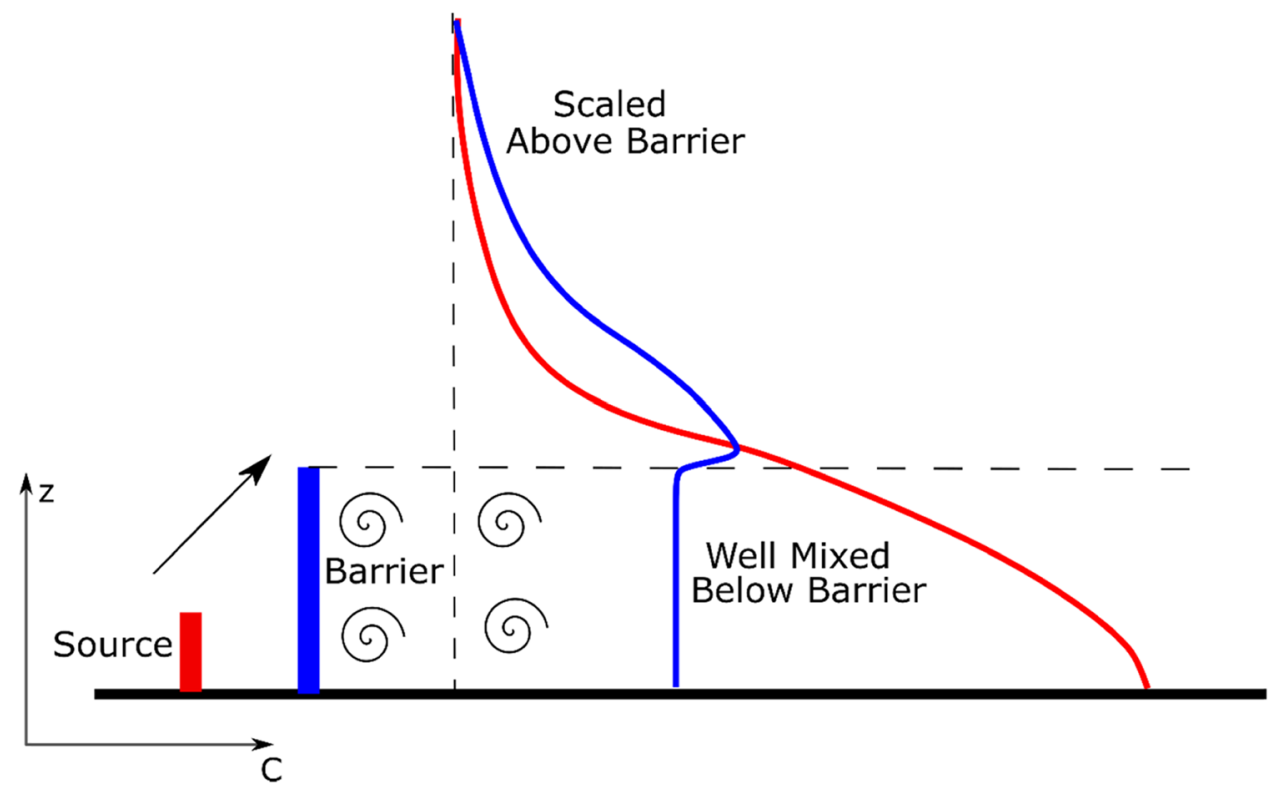

barrier, $x_{d}$, is the shortest distance along the wind direction between the receptor and the barrier.

The effective wind velocity, $U_{e}$ in Eq. 2 is given by

$U_{e}=\sqrt{\left(2 \sigma_{v}^{2}+U\left(\bar{z}+h_{o}\right)^{2}\right)}$,

where $\sigma_{\mathrm{v}}$ is the standard deviation of the horizontal wind speed, is the average vector wind speed at the mean plume height, $\bar{z}$. The mean plume height, $\bar{z}$, is related to the vertical plume spread, which in turn is a function of $U_{e}$. So these parameters are computed iteratively (Venkatram et al. 2013b) from

$\sigma_{z}=f\left(x, u_{*}, L, U_{e}\left(h_{o}\right)\right)$,

where

$f\left(x, u_{*}, L, U_{e}\right)=\left\{\begin{array}{c}0.57 \frac{u_{*}}{U_{e}}\left(1-1.5 \frac{u_{*}}{U_{e}} \frac{x}{L}\right) ; L<0 \\ 0.57 \frac{u_{*}}{U_{e}} x\left(1+3 \frac{u_{*}}{U_{e}}\left(\frac{x}{L}\right)^{\frac{2}{3}}\right)^{-1} ; L>0\end{array}\right.$

$\bar{z}=\sigma_{z} \sqrt{\frac{2}{\pi}} \exp \left(-\frac{1}{2}\left(\frac{z_{s}}{\sigma_{z}}\right)^{2}\right)+z_{s} \operatorname{erf}\left(\frac{z_{s}}{\sqrt{2} \sigma_{z}}\right)$

Equation 5 breaks down when $\theta=90^{\circ}$ because of the $\cos \theta$ in the denominator. The term $\sigma_{z} \cos \theta$ (Venkatram et al. 2013a) is modified as follows to avoid this,

$\sigma_{z}\left(x_{d}\right) \cos \theta=\frac{\sigma_{z}\left(x_{d} \cos \theta\right)+\sigma_{z}\left(x_{d}\right) \cos \theta}{2}$
Vertical mixing occurs when the plume travels from the line source to the barrier. This mixing is also enhanced by the movement of vehicles on the freeway. The vertical plume spread due to this vertical mixing is added to the vertical spread between the line source and barrier,

$\sigma_{z_{o}}=\sqrt{\sigma_{z}\left(x_{s}, u_{* b}, L, U_{e}(0)\right)^{2}+h_{v}^{2}}$,

where $x_{s}$ is the downwind distance from the line source to the barrier and $h_{v}=1.5 \mathrm{~m}$ is the effective height of the vehicles traveling on the freeway. Then, the vertical spread between the source and barrier is accounted for in the vertical spread downwind of the barrier through a virtual distance, $x_{o}$, computed from the implicit equation

$\sigma_{z_{o}}=f\left(x_{o}, u_{* b}, L, U_{e}\left(h_{o}\right)\right)$,

where $u_{* b}$ is the friction factor that accounts for enhanced turbulence downwind of the barrier which will be discussed in the next section. The virtual distance, $x_{o}$, is added to the downwind distance, $x_{d}$, from the barrier to the receptor.

\section{$u_{*}$ correction}

The presence of the barrier increases turbulent mixing downwind of the barrier as measured in various studies (Heist et al. 2009). This increase in turbulence is accounted for by increasing the friction velocity, $u_{*}$ near the barrier as follows, 
$z_{o_{b}}=\max \left(\frac{h_{o}}{9}, z_{o}\right)$

$u_{* b}=u_{*}\left(\frac{z_{o_{b}}}{z_{o}}\right)^{0.17}$

The friction velocity was used to compute a modified Monin-Obukhov length assuming that the heat flux does not change. The modified friction velocity, $u_{* b}$, recovers to its upwind value over a length scale determined empirically to be $5 h_{o}$. Then,

$u_{* c}=u_{* b} f_{m}+u_{*}\left(1-f_{m}\right)$

$f_{m}=\exp \left(-\frac{x_{d}}{5 h_{o}}\right)$

where $u_{*_{c}}$ is the corrected friction velocity used in computing the vertical spread of the plume. The factor $f_{m}$ tends to 1 near the barrier and zero at downwind distances that are several times the height of the barrier.

\section{Entrainment factor, $\mathbf{f}_{\mathrm{e}}$}

When the wind speeds are low, the model overestimated concentrations, which suggested decreasing the entrainment factor, $f_{e}$, to values below unity in this situation. This effect is illustrated in Fig. 7, which shows the ratio of the mean modeled concentration to the mean measured concentration $\left(C_{p} / C_{o}\right)$ versus the upwind friction velocity, $u_{*}$. The mean modeled concentrations are close to 3.5 times the measured concentrations when $u_{*}$ is less than $0.1 \mathrm{~m} / s$ and the

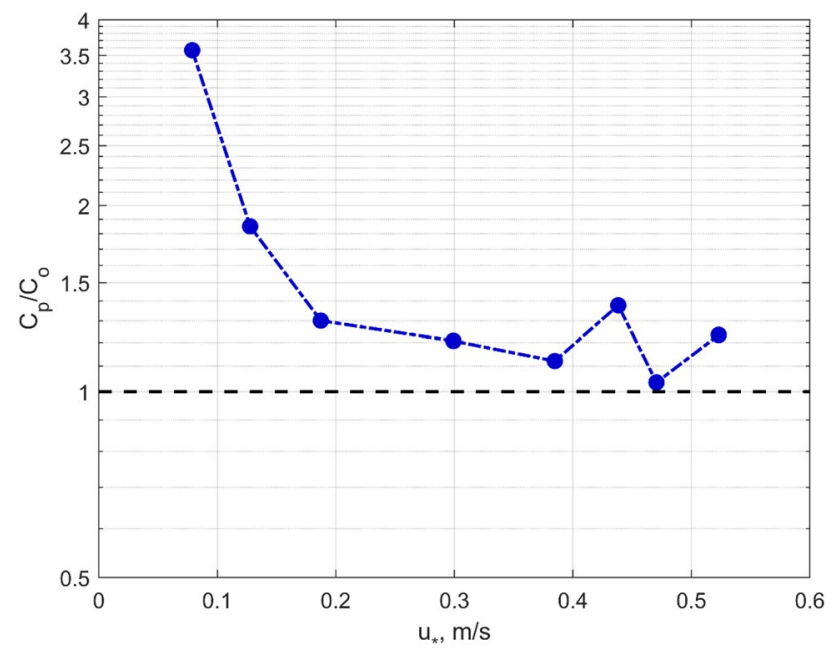

Fig. 7 Plot between the ratio of the modeled to the measured concentration without the entrainment factor $\left(f_{e}=1\right)$. The overpredictions decrease with increasing $u_{*}$ overestimation decreases with increasing $u_{*}$. This suggested the following empirical relation,

$f_{e}=\frac{u_{* b}}{u_{* b}+u_{* o}}$

where $u_{* o}=0.1 \mathrm{~m} / \mathrm{s}$. $f_{e}$ tends to 1 as $u_{* b}$ increases. Equation (18) is designed to reflect the possibility that the turbulence generated by wind shear at the top of the barrier becomes less effective in entraining the plume above the barrier as the wind speeds approach zero.

\section{Model performance and barrier effects}

Model performance is summarized in Table 4 using the coefficient of regression between the 1-h averaged measured and modeled $S F_{6}$ concentrations, $R^{2}$, and median of the ratio between the 1 -h averaged modeled and measured $S F_{6}$ concentrations, $m_{g}$. The deviation of $m_{g}$ from 1 quantifies the overall bias in the model. An $m_{g}$ value less than 1 points to underprediction and vice versa. On days 1 and 2, the model performs well both with and without the entrainment factor. The $R^{2}$ and $m_{g}$ are 0.90 and 0.99 respectively on day 1 without the entrainment factor, and are 0.91 and 0.88 with the entrainment factor. The $R^{2}$ and $m_{g}$ are 0.75 and 1.12 on day 2 without the entrainment factor, and 0.75 and 1 with the entrainment factor.

The model overestimates measurements on day 3 without the entrainment factor with $m_{g}$ of 2.21 and $R^{2}$ of 0.49 . When the entrainment factor is included in the model, performance improves with $m_{g}$ of 1.35 and $R^{2}$ of 0.53 . On day 4 , the inclusion of the entrainment factor improves the results with the $R^{2}$ and $m_{g}$ improving from 0.87 and 1.19 without the entertainment factor to 0.89 and 0.93 with the entrainment factor.

Figure 8 shows the plot with the $S F_{6}$ concentration on the vertical axis and the distance from the barrier on the horizontal axis. The concentration data was averaged based on the distance from the barrier using 25-m-long bins. The measured concentrations are represented by blue squares while the modeled concentrations are represented by red circles. The plots on the left panels show results without

Table 4 Performance statistics of the scaled barrier model 
Without Entrainment Factor
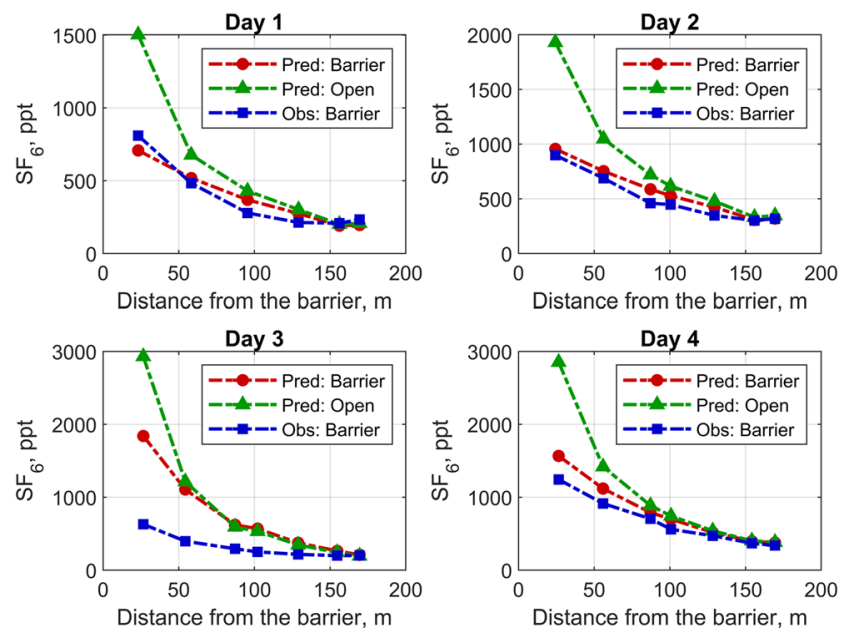

Fig. 8 Plot showing the $S F_{6}$ concentration with the distance from the barrier. The measured concentrations with the barrier are indicated by blue squares, the modeled concentrations with the barrier are shown

the entrainment factor, i.e., $f_{e}=1$ and the plots on the right show results with $f_{e}$ given by Eq. 18 . The overpredictions on day 3 , when the wind speeds are low, are reduced when the entrainment factor is incorporated, as seen in the right panel.

The effect of the barrier was studied by running the scaled barrier model with no barrier $\left(h_{o}=0\right.$, Open $)$ and comparing with results with the barrier $\left(h_{o}=5 \mathrm{~m}\right.$, Barrier $)$. The modeled concentrations without the barrier are denoted by green triangles in Fig. 8 . The reduction in concentrations due to the barrier is more than $50 \%$ close to the freeway and becomes small at downwind distances greater than $150 \mathrm{~m}$ or 25 times the barrier height. These results are consistent with previous studies on the mitigation effects of barriers (Baldauf et al. 2008; Heist et al. 2009; Finn et al. 2010).

\section{Conclusions}

This is the first tracer study designed to examine the mitigating effect of noise barriers under real-world conditions. The data collected from the field study will be used to evaluate dispersion models that incorporate the effects of solid barriers.

An examination of the data showed that the downwind variation of the tracer concentration is consistent with the results from the simple model described by Eq. (1). This model is based on the idea that the mitigating effect of a sound barrier on near-road air quality is equivalent to shifting the source, the road, by the height of the barrier divided by the upwind turbulent intensity. This equation is a rule-of-thumb for estimating the impact of a sound barrier on downwind concentrations as a function of distance from a road.
With Entrainment Factor
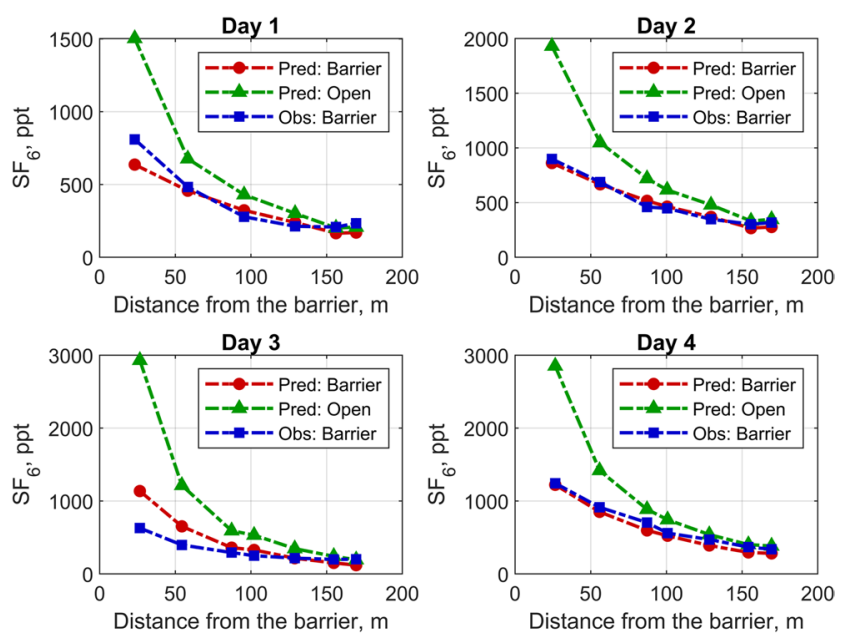

with red circles, and the modeled concentrations without the barrier are shown by green triangles

We then probed the data using a dispersion model that incorporated the major processes responsible for the mitigating impact of a barrier: lifting of the plume above the barrier followed by entrainment of the elevated plume into the wake of the barrier. The model provided an adequate description of the measured concentrations except when the wind speeds were less than $1 \mathrm{~m} / \mathrm{s}$ : the model overestimated measured concentrations by a factor of three. We propose an approach to reduce this overestimation through a function that depends on the upwind friction velocity.

Acknowledgements We are grateful to the California Department of Transport (Caltrans) for supporting the research described in this paper. We are also thankful to all the undergraduate students whose participation was crucial to the success of the field study. Drs. Simon Bisrat and Yoojoong Choi from Caltrans, and their Advisory Committee provided important input that improved the planning and implementation of the field study.

Data availability Data will become available to the public after Caltrans releases it in 2023.

\section{Declarations}

Conflict of interest The authors declare no competing interests.

Open Access This article is licensed under a Creative Commons Attribution 4.0 International License, which permits use, sharing, adaptation, distribution and reproduction in any medium or format, as long as you give appropriate credit to the original author(s) and the source, provide a link to the Creative Commons licence, and indicate if changes were made. The images or other third party material in this article are included in the article's Creative Commons licence, unless indicated otherwise in a credit line to the material. If material is not included in the article's Creative Commons licence and your intended use is not permitted by statutory regulation or exceeds the permitted use, you will need to obtain permission directly from the copyright holder. To view a copy of this licence, visit http://creativecommons.org/licenses/by/4.0/. 


\section{References}

Baldauf R, Thoma E, Khlystov A et al (2008) Impacts of noise barriers on near-road air quality. Atmos Environ 42:7502-7507. https:// doi.org/10.1016/j.atmosenv.2008.05.051

Brandt S, Perez L, Künzli N et al (2014) Cost of near-roadway and regional air pollution-attributable childhood asthma in Los Angeles County. J Allergy Clin Immunol 134:1028-1035. https://doi. org/10.1016/j.jaci.2014.09.029

Chen Z, Newgard CB, Kim JS et al (2019) Near-roadway air pollution exposure and altered fatty acid oxidation among adolescents and young adults - the interplay with obesity. Environ Int 130:104935. https://doi.org/10.1016/j.envint.2019.104935

Cimorelli AJ, Perry SG, Venkatram A et al (2005) AERMOD: a dispersion model for industrial source applications. Part I: General model formulation and boundary layer characterization. J Appl Meteorol 44:682-693. https://doi.org/10.1175/ JAM2227.1

Finn D, Clawson KL, Carter RG et al (2010) Tracer studies to characterize the effects of roadside noise barriers on near-road pollutant dispersion under varying atmospheric stability conditions. Atmos Environ 44:204-214. https://doi.org/10.1016/j.atmosenv. 2009.10.012

Hagler GSW, Tang W, Freeman MJ et al (2011) Model evaluation of roadside barrier impact on near-road air pollution. Atmos Environ 45:2522-2530. https://doi.org/10.1016/j.atmosenv.2011.02.030
Heist DK, Perry SG, Brixey LA (2009) A wind tunnel study of the effect of roadway configurations on the dispersion of trafficrelated pollution. Atmos Environ 43:5101-5111. https://doi.org/ 10.1016/j.atmosenv.2009.06.034

Schulte N, Snyder M, Isakov V et al (2014) Effects of solid barriers on dispersion of roadway emissions. Atmos Environ 97:286-295. https://doi.org/10.1016/j.atmosenv.2014.08.026

Venkatram A, Horst TW (2006) Approximating dispersion from a finite line source. Atmos Environ 40:2401-2408. https://doi.org/ 10.1016/j.atmosenv.2005.12.014

Venkatram A, Schulte N (2018) Modeling dispersion at city scale. Urban Transp Air Pollut 139-146. https://doi.org/10.1016/b9780-12-811506-0.00006-3

Venkatram A, Isakov V, Thoma E, Baldauf R (2007) Analysis of air quality data near roadways using a dispersion model. Atmos Environ 41:9481-9497. https://doi.org/10.1016/j.atmosenv.2007.08.045

Venkatram A, Snyder M, Isakov V, Kimbrough S (2013a) Impact of wind direction on near-road pollutant concentrations. Atmos Environ 80:248-258. https://doi.org/10.1016/j.atmosenv.2013.07.073

Venkatram A, Snyder MG, Heist DK et al (2013b) Re-formulation of plume spread for near-surface dispersion. Atmos Environ 77:846-855. https://doi.org/10.1016/j.atmosenv. 2013.05.073

Publisher's note Springer Nature remains neutral with regard to jurisdictional claims in published maps and institutional affiliations. 